\title{
Chapter 2 \\ Theories in Mathematics Education as a Scientific Discipline
}

\author{
Angelika Bikner-Ahsbahs and Andreas Vohns
}

This first chapter of the survey addresses the historical situation of the community of mathematics education in German-speaking countries from the 1970s to the beginning 21st century and its discussion about the concept of theories related to mathematics education as a scientific discipline both in German-speaking countries and internationally.

\subsection{How to Understand Theories and How They Relate to Mathematics Education as a Scientific Discipline: A Discussion in the 1980s}

On an institutional and organizational level, the 1970s and early 1980s were a time of great change for mathematics education in the former West Germany ${ }^{1}$ — both in school and as a research domain. The Institute for Didactics of Mathematics (Institut für Didaktik der Mathematik, IDM) was founded in 1973 in Bielefeld as the first research institute in a German-speaking country specifically dedicated to mathematics education research. In 1975 the Society of Didactics of Mathematics

\footnotetext{
${ }^{1}$ For an overview including the development in Austria, see Dörfler (2013b); for an account on the development in Eastern Germany, see Walsch (2003).
}

\footnotetext{
A. Bikner-Ahsbahs $(\bowtie)$

Faculty of Mathematics and Information Technology, University of Bremen,

Bibliothekstrasse 1, 28359 Bremen, Germany

e-mail: bikner@math.uni-bremen.de
}

\author{
A. Vohns \\ Department of Mathematics Education, Alpen-Adria-Universität Klagenfurt, \\ Sterneckstraße 15, 9020 Klagenfurt, Austria \\ e-mail: andreas.vohns@aau.at \\ (C) The Author(s) 2016 \\ A. Bikner-Ahsbahs et al., Theories in and of Mathematics Education, \\ ICME-13 Topical Surveys, DOI 10.1007/978-3-319-42589-4_2
}


(Gesellschaft für Didaktik der Mathematik, GDM) was founded as the scientific society of mathematics educators in German-speaking countries (see Bauersfeld et al. 1984, pp. 169-197; Toepell 2004).

The teachers' colleges (Pädagogische Hochschulen), at that time the home of many mathematics educators, were either integrated into full universities or developed into universities of education that were entitled to award doctorates. The Hamburg Treaty (Hamburger Abkommen, KMK 1964/71) adopted in 1964 by the Standing Conference of Ministers of Education and Cultural Affairs (KMK) led to considerable organizational changes within the German school system. The traditional Volksschule (a common school covering both primary and secondary education, Grades 1-8) was abolished and led to an even more differentiated secondary school system, establishing two types of secondary schools called Hauptschule and Realschule in addition to the already established Gymnasium. The Hamburg Treaty also abolished the designations of the school subjects dedicated to mathematics education, which was traditionally called Rechnen (translates as "practical arithmetic") in the Volksschule and as Mathematik in Gymnasium (see Griesel 2001; Müller and Wittmann 1984, pp. 146-170).

Likewise, there was a strong interest in discussing how far mathematics education had developed as a scientific discipline, as documented in both of the German-language journals on mathematics education founded at that time: the Zentralblatt für Didaktik der Mathematik (ZDM, founded in 1969) and the Journal für Mathematik-Didaktik (JMD, founded in 1980). In these discussions, two main aspects were addressed: the role and suitable concept of theories for mathematics education and how mathematics education as a scientific discipline was to be founded and could be further developed. However, both aspects are deeply intertwined.

Issue 6 (1974) of $Z D M$ was dedicated to a broad discussion of the current state of the field of "Didactics of Mathematics"/mathematics education. The issue was edited by Hans-Georg Steiner and included contributions from Bigalke (1974), Freudenthal (1974), Griesel (1974), Otte (1974), and Wittmann (1974), among others. These articles were focused around the questions of (1) how to conceptualize the subject area or domain of discourse of mathematics education as a scientific discipline, (2) how mathematics education may substantiate its scientific character, and (3) how to frame its relation to reference disciplines, especially mathematics, psychology, and educational science. While there has been a great diversity in the approaches to these questions and, likewise, to the definitions of "Didactics of Mathematics" given by the various authors, cautioning against reductionist approaches seemed to be a common topic of these papers. That is, the authors agreed upon the view that mathematics education cannot be meaningfully conceptualized as a subdomain of mathematics, psychology, or educational science alone.

The role of theory was more explicitly discussed about 10 years later in two papers (Burscheid 1983; Bigalke 1984) and in two comments (Fischer 1983; Steiner 1983) published in the JMD. As an example of the discussion about theory at that time, we will convey the different positions in these papers in more detail. 
In 1983, Burscheid used the model of Kuhn and Masterman (see Kuhn 1970; Masterman 1970) to explore the developmental stage of mathematics education as a scientific discipline. He justified this approach by claiming that every science represents its results through theories and therefore mathematics education as a science is obliged to develop theories and make its results testable (Burscheid 1983, p. 222). The model of Kuhn and Masterman describes scientific communities and their development using paradigms. By investigating mainly natural sciences, Kuhn has characterized a paradigm by four components:

1. Symbolic generalizations: "expressions, deployed without question or dissent..., which can readily be cast in a logical form" (Kuhn 1970, p. 182) or a mathematical model: in other words, scientific laws, e.g., Newton's law of motion.

2. Metaphysical presumptions: as faith in specific models of thought or "shared commitment to beliefs," such as "heat is the kinetic energy of the constituent parts of bodies" (ibid., p. 184).

3. Values: attitudes "more widely shared among different communities" (ibid., p. 184) than the first two components.

4. Exemplars: such as "concrete problem-solutions that students encounter from the start of their scientific education" (ibid., p. 187): in other words, textbook or laboratory examples.

Masterman (1970, p. 65) ordered these components by three types of paradigms:

(a) Metaphysical or meta-paradigms (refers to 2),

(b) Sociological paradigms (refers to 3), and

(c) Artefact or constructed paradigms (refers to 1 and 4).

Each paradigm shapes a disciplinary matrix according to which new knowledge can be structured, legitimized, and imbedded into the discipline's body of knowledge. Referring to Masterman, Burscheid used these types of paradigms to identify the scientific state of mathematics education in the development of four stages of a scientific discipline (see Burscheid 1983, pp. 224-227):

1. Non-paradigmatic science,

2. Multi-paradigmatic science,

3. Dual-paradigmatic science, and

4. Mature or mono-paradigmatic science (ibid., p. 224, translated $^{2}$ ).

In the first stage, scientists originate the science by identifying its problems, establishing typical solutions, and developing methods to be used. In this stage, scientists struggle with the discipline's basic assumptions and a kernel of ideas; for instance, methodological questions of how validity can be justified and which thought models are relevant. In this stage, paradigms begin to develop, resulting in the building of scientific schools and shaping a multi-paradigm discipline. The schools' specific paradigms unfold locally within the single scientific group but do

\footnotetext{
${ }^{2}$ Any translation within this article has been conducted by the authors unless stated otherwise.
} 
not affect the discipline as a whole. In stage three, mature paradigms compete to gain scientific hegemony in the field (Burscheid 1983, p. 226). The final stage is that of a mature scientific discipline in which the whole community shares more or less the same paradigm (ibid., p. 226).

Following the disciplinary matrix, Burscheid (pp. 226-236) identified paradigms in mathematics education and features at that time, according to which different scientific schools emerged and could be distinguished from one another, e.g., according to forms, levels, and types of schools, or according to reference disciplines such as mathematics, psychology, pedagogy, and sociology. The constructed paradigms dealt in principle with establishing adequate theories in a discipline. Concerning building theories, however, the transfer of the model of Masterman and Kuhn was difficult to achieve because symbolic generalizations and/or scientific laws can be built more easily in the natural sciences than in mathematics education. This is because mathematics education is concerned with human beings who are able to creatively decide and act in the teaching and learning processes. Burscheid doubted that a general theory such as those in physics could ever be developed in mathematics education (ibid., p. 233). However, his considerations led to the conclusion that "there are single groups in the scientific community of mathematics education which are determined by a disciplinary matrix.... That means that mathematics education is [still] heading to a multi-paradigm science" (ibid., p. 234, translated).

Burscheid's analysis was immediately criticized from two perspectives. Fischer $(1983)^{3}$ claimed that pitting mathematics education against the scientific development of natural science is almost absurd because mathematics education has to do with human beings (ibid., p. 241). In his view, "theory deficit" (ibid., p. 242, translated) should not be regarded as a shortcoming but as a chance for all people involved in education to emancipate themselves. The lack of impact on practice should not be overcome by top-down measures from the outside but by involving mathematics teachers bottom-up to develop their lessons linked to the development of their personality and their schools (ibid., p. 242). Fischer did not criticize Burscheid's analysis per se, but rather the application of a model postulating that all sciences must develop in the same way as the natural sciences towards a unifying paradigm (Fischer 1983).

Steiner (1983) also criticized the use of the models developed by Kuhn and Masterman. He considered them to be not applicable to mathematics education in principle, claiming that even for physics these models do not address specific domains in suitable ways, and in his view domain specificity is in the core of mathematics education (ibid., p. 246). Even more than Fischer, Steiner doubted that mathematics education would develop towards a unifying single-paradigm science. According to him, mathematics education has many facets and a systemic character

\footnotetext{
${ }^{3}$ Fischer also feared that if mathematics education developed towards a unifying paradigm, the field would be more concerned with its own problems, as was the case with physics, and, finally, would develop with its issues separated from societal concerns.
} 
with a responsibility to society. It is deeply connected to other disciplines and, in contrast to physics, mathematics education must be thought of as being interdisciplinary at its core. The scientific development of mathematics education should not rely upon external categories of description and acceptance standards, but should develop such categories itself (ibid., pp. 246-247), and, moreover, it should consider the relation between theory and practice (ibid., p. 248).

Exactly such an analysis from the inside was proposed by Bigalke (1984) one year later. He analysed the development of mathematics education as a scientific discipline as well, but this time without using an external developmental model. He proposed a "suitable theory concept" (ibid., p. 133, translated) for mathematics education on the basis of nine theses. Bigalke urged a theoretical discussion and reflection on epistemological issues of theory development. Mathematics education should establish the principles and heuristics of its practice, specifically of its research practice and theory development, on its own terms. Bigalke specifically regarded it as a science that is committed to mathematics as a core area with relations to other disciplines. He claimed that its scientific principles should be created by "philosophical and theoretical reflections from tacit agreements about the purpose, aims, and the style of learning mathematics as well as the problematisation of its pre-requisites" (ibid., p. 142, translated).

Such principles are deeply intertwined with research programs and their theorizing processes. Many examples taken from the German didactics of mathematics were used to substantiate that Sneed's and Stegmüller's understanding of theory (see Jahnke 1978, pp. 70-90) fits mathematics education much better than the restrictive notion of theory according to Masterman and Kuhn, specifically when theories are regarded to inform practice. Bigalke (1984) described this theory concept in the following way:

\footnotetext{
A theory in mathematics education is a structured entity shaped by propositions, values and norms about learning mathematics. It consists of a kernel, which encompasses the unimpeachable foundations and norms of the theory, and an empirical component which contains all possible expansions of the kernel and all intended applications that arise from the kernel and its expansions. This understanding of theory fosters scientific insight and scientific practice in the area of mathematics education. (p. 152, translated)
}

Bigalke himself pointed out that this understanding of theory allows many theories to exist side by side. It was clear to him that no collection of scientific principles for mathematics education would result in a "canon" agreed to across the whole scientific community. On the contrary, he considered a certain degree of pluralism and diversity of principles and theories to be desirable or even necessary (ibid., p. 142). Bigalke regarded theories as the link to the practice of teaching and learning of mathematics as well as being inspired by this practice, founding mathematics education as a scientific discipline in which theories may prove themselves successful in research and practice (Bigalke 1984). 


\subsection{Theories of Mathematics Education (TME): A Program for Developing Mathematics Education as a Scientific Discipline}

Out of the previous presentation arose the result that the development of theories in mathematics education cannot be cut off from clarifying the notion of theory and its epistemological ground related to the scientific foundation of the field. Steiner (1983) construed this kind of self-reflection as a genuine task in any scientific discipline (see Steiner 1986) when he addressed the comprehensive task of founding and further developing mathematics education as a scientific discipline (see Steiner 1987c). At a post-conference meeting of ICME5 in Adelaide in 1984, the first of five conferences on the topic "Theories of Mathematics Education" (TME) took place (Steiner et al. 1984; Steiner 1985, 1986). This topic is a developmental program consisting of three partly overlapping components ${ }^{4}$ :

- Development of the dynamic regulating role of mathematics education as a discipline with respect to the theory-practice interplay and interdisciplinary cooperation.

- Development of a comprehensive view of mathematics education comprising research, development, and practice by means of a systems approach.

- Meta-research and development of meta-knowledge with respect to mathematics education as a discipline (emphasis in the original; Steiner 1985, p. 16).

Steiner characterized mathematics education as a complex referential system in relation to the aim of implementing and optimizing teaching and learning of mathematics in different social contexts (ibid., p. 11). He proposed taking this view as "a meta-paradigm for the field" (ibid., p. 11; Steiner 1987a, p. 46), addressing the necessity of "meta-research in the field." According to Steiner, the field's inherent complexity evokes reduction of its complexity in favour of focusing on specific aspects, such as curriculum development, classroom interaction, or content analysis. According to Steiner, this complexity also creates a differential classification of mathematics education as a "field of mathematics, as a special branch of epistemology, as an engineering science, as a sub-domain of pedagogy or general didactics, as a social science, as a borderline science, as an applied science, as a

\footnotetext{
${ }^{4}$ This program was later reformulated by Steiner (1987a, p. 46):

- Identification and elaboration of basic problems in the orientation, foundation, methodology, and organization of mathematics education as a discipline

- The development of a comprehensive approach to mathematics education in its totality when viewed as an interactive system comprising research, development, and practice

- Self-referent research and meta-research related to mathematics education that provides information about the state of the art- the situation, problems, and needs of the discipline-while respecting national and regional differences.
} 
foundational science, etc." (Steiner 1985, p. 11). Steiner required clarification of the relations among all these views, including the principle of complementarity on all layers, which means considering research and meta-research, concepts as objects and concepts as tools (Steiner 1987a, p. 48, 1985, p. 15). He proposed understanding mathematics education as a human activity; hence, he added an activity theory view to organize and order the field (Steiner 1985, p. 15). The interesting point here is that Steiner implicitly adopted a specific theoretical view of the field but points to the multiple perspectives in the field, which should be acknowledged as its interdisciplinary core.

Steiner (1985) emphasized the need for the field to become aware of its own processes of development of theories and models and investigate its means, representations, and instruments. Epistemological considerations seemed important for him, specifically concerning the role of theory and its application. In line with Bigalke, he proposed considering Sneed's view on theory as suitable for mathematics education, since it encompasses a kernel of theory and an area of intended applications to conceptualize applicability being a part of the very nature of theories in mathematics education (ibid., p. 12).

In the first TME conference, theory was an important topic, specifically the distinction between so-called borrowed and home-grown theories. Steiner's complementary view made him point to the danger of one-sidedness. In his view, so-called borrowed theories are not just transferred and used but rather adapted to the needs of mathematics education and its specific contexts. Home-grown theories are able to address domain-specific needs but are subjected to the difficulty of establishing suitable research methodologies on their own authority. The interdisciplinary nature of mathematics education requires regulation among the perspectives but also regulation of the balance between home-grown and borrowed theories (Steiner 1985; Steiner et al. 1984).

So, what is Steiner's specific contribution to the discussion of theories and theory development? Like other colleagues, such as Bigalke, he has pointed to the role of theories as being in the core of mathematics education as a scientific discipline, and he proposed the notion of theory developed by Sneed and Stegmüller (see Jahnke 1978, pp. 70-90) as being suitable for such an applied science. Steiner proposed complementarity to be a guiding principle for the scientific field and required investigating what complementarity means in each case of the field's topics. In this respect, the dialectic between borrowed theories and home-grown theories is an integral part of the field that allows the discipline to develop from its core and to be challenged from its periphery. In addition, Steiner emphasized that mathematics education as a system should reflect about its own epistemological basis, its own theory concepts and theory development, the relation between theory and practice, and the interrelation among all its perspectives. He has added that the specific view of mathematics education always incorporates some epistemological model of how mathematics and teaching and learning of mathematics are understood and that this is especially relevant for theories in mathematics education. 


\subsection{Post-TME Period}

In the following decade, from 1992 up to the beginning of the 21st century, the discussion on theory concepts died down in the German community of mathematics educators while the theoretical diversity in the field grew. Considering the two main scientific journals, we identified scientific contributions from several theoretical communities addressing three topics related to the TME program (without any claim of completeness):

1. Methodology: methodological and thus theoretical aspects in interpretative research (Beck and Jungwirth 1999), interviews in empirical research (Beck and Maier 1993), multi-methods (Wellenreuther 1997); explaining in research (Maier 1998), methodological considerations on TIMSS (Knoche and Lind 2000);

2. Methods in empirical research: e.g., two special issues of ZDM in 2003 edited by Kaiser presented a number of methodical frameworks; and

3. Issues on meta-research about what mathematics education is, can, and should include: considerations on paradigms and the notion of theory in interpretative research (Maier and Beck 2001), comparison research (Kaiser 2000; Maier and Steinbring 1998; Brandt and Krummheuer 2000; Jungwirth 1994), and mathematics education as design science (Wittmann 1995) and as a text science (Beck and Maier 1994).

This short list indicates that - at that time-distinct theoretical communities seemed to share the need for methodological and meta-theoretical reflection. However, the German community of mathematics education as a whole did notand still does not-share a common paradigm. In order to provide deeper insight into theory strands of German-speaking countries, two examples are presented.

The first one is the theory of learning activity that originates in activity theory developed by Joachim Lompscher. It is used today in several educational subjects: for example, Bruder has further developed and adapted this concept to the needs of mathematics education, and she and Schmitt will present this theory strand. The second theory strand is a specific view on semiotics presented by Dörfler and contrasted with Otte's view on signs as a vehicle for doing mathematics as a human activity.

The theory of learning activity provides a general educational theory that has been borrowed then applied and adapted to mathematics education, while Dörfler bases his work profoundly in the philosophies of Peirce and Wittgenstein and reconstructs mathematics as a kind of game using diagrams in a more home-grown way.

Open Access This chapter is distributed under the terms of the Creative Commons Attribution 4.0 International License (http://creativecommons.org/licenses/by/4.0/), which permits use, duplication, adaptation, distribution and reproduction in any medium or format, as long as you give appropriate credit to the original author(s) and the source, a link is provided to the Creative Commons license and any changes made are indicated. 
The images or other third party material in this chapter are included in the work's Creative Commons license, unless indicated otherwise in the credit line; if such material is not included in the work's Creative Commons license and the respective action is not permitted by statutory regulation, users will need to obtain permission from the license holder to duplicate, adapt or reproduce the material. 